\title{
O papel das emoções, através do Design, na elicitação da autoestima
}

The role of emotions from the Design perspective to self-steem elicitation

\author{
ANDRADE, Rebeca Medeiros de; Mestranda; PGDesign - UFRGS \\ rebeca.andrade@ufrgs.br \\ TEIXEIRA, Fábio Gonçalves; Doutor; PGDesign - UFRGS \\ fabiogt@ufrgs.br
}

\section{Resumo}

As emoções representam um fator significativo na relação do consumidor com produtos e serviços. Nesse sentido, a proposta deste trabalho consiste na proposição de uma análise comparativa entre três tipos de próteses (entre transfemurais e transtibiais), abordando os aspectos emocionais que influenciam a intenção e também a decisão de compra. Para tanto, foi realizada uma revisão de literatura abordando os temas Design e Emoção, Tecnologia Assistiva, mercado de Órteses, Próteses e Materiais Especiais e também aspectos relacionados a Estética e Autoestima. Também foi realizada uma pesquisa por meio de questionário online com 12 usuários desse tipo de produto. Como conclusão, demonstra-se que o consumo de produtos por motivações estéticas podem, muitas vezes, equiparar ou superar as motivações funcionais e também de desempenho, já que esse tipo de produto tem o poder de gerar diferentes tipos e intensidades de emoções, atuando inclusive como uma extensão da personalidade e identidade do indivíduo.

Palavras Chave: Design Emocional; Tecnologia Assistiva; Autoestima.

\begin{abstract}
Emotions represent a very significant factor in the consumer's relationship with products and services. This article proposes a comparative analysis between three types of prosthesis, considering Above-knee Amputation (AKA) and Below-knee Amputation (BKA), addressing the emotional aspects which influences the intention and also the purchase decision. For that, a literature review was performed to address the issues Design and Emotion, Assistive Technology, Orthoses, Special Materials and also aspects related to Aesthetics and Self-esteem. It was also submitted a survey through an online questionnaire with 12 prosthesis users. Finally, the research shows that consumption of products by aesthetic motivations can often equate or surpass the functional and performance motivations, since this type of product evokes different types and intensities of emotions, acting including as an extension of the individual's personality and identity.
\end{abstract}

Keywords: Emotional Design; Assistive Technology; Self-Esteem. 


\section{Introdução}

Sentimento de ruptura, estranhamento, insegurança e perda e/ou diminuição da autoestima são apenas alguns reflexos de aspectos emocionais presentes na vida de indivíduos submetidos à amputação de membros. De acordo com Wald e Álvaro (2004), os sintomas de depressão são mencionados como circunstâncias frequentes em indivíduos que passaram pelo processo de amputação, pois os mesmos manifestam quadros de tristeza e pesar, episódios de choro, isolamento social, perda ou diminuição de apetite e dificuldade para dormir, por exemplo. O sentimento de ruptura pode ser caracterizado pelo fato de a configuração atual do corpo do indivíduo não corresponder à anterior, e esse fato gera um estranhamento, já que existe uma configuração nova e discordante da qual o indivíduo era habituado. A insegurança surge da consciência de que agora, com essa nova configuração, o desempenho de algumas atividades poderá ficar comprometido. Não se enxergando mais como sendo o mesmo e se sentindo inseguro, o indivíduo começa a se colocar numa posição abaixo da qual vivia anteriormente, configurando-se assim uma situação de diminuição da autoestima, que é a capacidade de valorização e apreço que uma pessoa confere a si mesma, o que lhe permite ter confiança nos próprios atos e pensamentos.

Após o processo de aceitação de si mesmo posterior a amputação, inicia-se o processo de aceitação do uso de uma prótese, que é um dispositivo permanente ou temporário que substitui total ou parcialmente um membro, órgão ou tecido, conforme definição da Câmara Técnica de Implantes, disponível no site da Associação Brasileira de Importadores e Distribuidores de Implantes (Abraidi).

Considerando que o indivíduo certamente passará por um longo processo de adaptação que envolverá a incidência de diferentes tipos e intensidades de sentimentos e emoções, e ainda considerando que assim como qualquer outro tipo de bem de consumo semidurável, as próteses ortopédicas podem apresentar diferentes estilos e configurações, é natural o surgimento de alguns questionamentos, como: que tipo de prótese usar? Uma que imite um membro real ou uma que não apresente nenhuma semelhança com o mesmo? E como resolver a questão da compatibilidade de cor de pele? E como lidar com texturas e brilhos de certos materiais?

Enxergar o indivíduo que usa prótese ortopédica como um consumidor comum é um dos primeiros requisitos para que haja um aumento na qualidade estética dos produtos desenvolvidos e comercializados. Apesar de a beleza ser um conceito variável, pois o centro de existência do belo não está no objeto em si, mas no sujeito que o experiencia, e havendo diferentes juízos estéticos (ou juízos de gosto), conforme aponta o filósofo alemão Kant (1980), ainda acredita-se que investir em atributos estéticos é uma forma de atrair o consumidor a partir do apelo de vantagens hedônicas conferidas pelo produto, aliadas às vantagens de desempenho funcional.

Nesse sentido, o trabalho consiste em uma análise comparativa entre emoções positivas e emoções negativas geradas por 3 tipos de próteses (entre transfemurais e transtibiais) mais comumente utilizadas e comercializadas atualmente. Neste âmbito, foi feito um levantamento bibliográfico, para que a análise tenha embasamento teórico, atestando que o projeto de produtos focado na experiência do usuário pode influenciar positiva e diretamente na elicitação da autoestima. Para isso foi realizada pesquisa em materiais já publicados, tais como textos científicos e acadêmicos, periódicos e bibliografias que discorrem sobre o tema proposto, além de aplicação de questionário on-line com usuários reais de próteses transfemurais e transtibiais. 


\section{Referencial Teórico}

\subsection{Emoção e Design}

A partir do final da década de 1990 o cenário internacional do design presenciou o surgimento de um novo campo de estudo, pesquisa e produção, o campo denominado Design Emocional. Conforme apresentado por Tonetto (2011), essa área faz referência à profissionalização do ato de projetar com a intenção explícita de despertar ou de evitar determinadas emoções nos usuários.

Uma das formas de lidar com as emoções no âmbito do design é através da perspectiva estabelecida pela relação entre psicologia, design e pesquisa, no entanto é importante ressaltar que essa não é a única perspectiva possível. A dimensão emocional de um projeto pode também ser discutida a partir de uma grande diversidade de teorias, abordagens, áreas de conhecimento e métodos, conforme apontado por Tonetto e Costa (2011), em seu trabalho a respeito de conceitos, abordagens e perspectivas de pesquisa em Design Emocional.

Ao se abordar a relação existente entre emoção e design, faz-se necessária a referência ao emprego de teorias específicas provenientes da relação entre a psicologia, o design e a pesquisa, como já referido, evidenciando que a emoção pode ser um elemento previsível e até certo ponto controlável, já que o projeto de um produto pode atuar na conformação das experiências emocionais que são desejáveis pelos indivíduos.

A experiência emocional pode ser compreendida como sendo um dos três âmbitos da experiência, que de acordo com Hekkert (2006) são os seguintes: experiência estética (que é o grau em que os sentidos são contemplados), experiência de significado (que é o significado atribuído ao produto) e experiência emocional (constituída pelos sentimentos e emoções despertados). A partir dessa perspectiva surge o entendimento da expressão product experience (HEKKERT, 2006), que engloba todos esses conceitos relativos aos âmbitos da experiência, e que são promovidos pela interação estabelecida entre o usuário e o produto.

Ao se abordar o design para emoção, faz-se necessário reconhecer a existência do vínculo real entre esse campo e o campo referente a estética e/ou ao significado - assunto que será abordado de forma mais ampla no item 2.4 do presente trabalho, no qual serão expostos alguns conceitos referentes a Autoestima e Estética.

O Design Emocional é caracterizado como sendo uma das áreas científicas do design, já que atua com base em teorias, métodos e resultados de pesquisa que permitem a elaboração de afirmações a respeito da experiência. Esse caráter científico é caracterizado pelas etapas de projeto e pesquisa, que permitem ao profissional do design a observação, no contexto real, da efetiva aplicação de suas teorias embasadas em conceitos psicológicos e também de inspirações pessoais (por parte do designer), que são aplicados na forma de projeto. Desmet (2009) enfatizou que, em nível projetual, existem quatro formas de se trabalhar o design com foco nas emoções, são elas:

a) Com foco no usuário: envolve o usuário no projeto, e suas emoções são o foco do processo de design. Técnicas exploratórias são comumente empregadas, inclusive colagens, mockups, entre outras. 
b) Com foco no designer: designers atuam como autores e, mais que gratificar usuários, esses profissionais desafiam os consumidores, apresentando algo diferenciado.

c) Com foco em pesquisa: as diretrizes projetuais são frutos de pesquisa e/ou são testadas com usuários, comumente empregando técnicas de mensuração.

d) Com foco em teoria: a teoria auxilia a qualificar o design em termos de impacto emocional. Nessa visão, insights teóricos ajudam a desenvolver conceitos.

Para esclarecer alguns conceitos e termos próprios referentes a abordagens relacionadas ao vínculo entre emoção e design, faz-se necessário exemplificar através de um modelo já existente. A interação existente entre um produto e os interesses e objetivos dos usuários (também denominados concerns) resultam nas avaliações dos usuários (appraisals), que levam a emoções, como mostra a Figura 1.

Figura 1 - Modelo básico de compreensão sobre emoções em relação a produtos

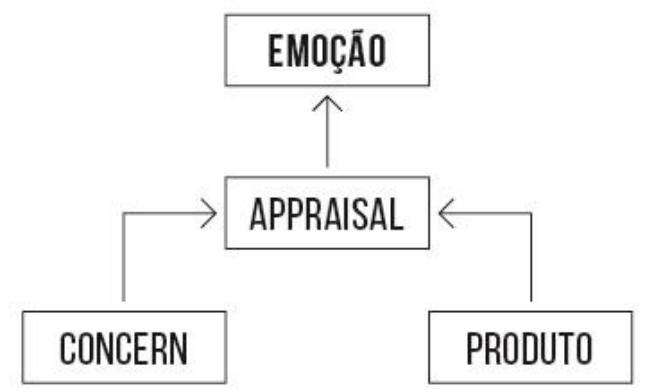

Fonte: Adaptado de Desmet e Hekkert, 2007, p. 62

O objetivo de se apresentar essa figura é esclarecer o fato de que as emoções são entendidas, nessa teoria, como sendo o resultado de avaliações (appraisals) dos usuários. Portanto, projetar para emoções significa entender como o produto se relaciona com os interesses (concerns) dos usuários-consumidores.

\subsection{Tecnologia Assistiva}

De acordo com a Assistive Technology Act, de 1998, Tecnologia Assistiva compreende qualquer item adquirido comercialmente (podendo ser parte de equipamento ou equipamento assistivo), modificado ou personalizado, que é usado com a finalidade de melhorar o desempenho da capacidade funcional de um indivíduo com deficiência. Tecnologias Assistivas podem ser de baixa ou alta tecnologia.

Conforme aponta Leite (2016), atualmente existem sete classes diferentes de Tecnologia Assistiva, sendo elas: adaptações cognitivas, adaptações no meio ambiente (residencial, escolar, profissional e público), adaptações que facilitam o acesso ao computador, adaptações veiculares, adequação postural em cadeira de rodas, comunicação alternativa (suplementar ou aumentativa) e equipamentos usados para esporte e recreação. Todas as sete classes citadas constituem focos reais de pesquisas e intervenções clínicas, o que justifica os crescentes avanços tecnológicos que 
impactam diretamente no desenvolvimento de aparatos assistivos.

O uso de equipamentos assistivos podem auxiliar indivíduos com deficiência para que haja um melhor desempenho de suas atividades diárias, desde as básicas até as instrumentais, visando sempre proporcionar máximo potencial possível de independência ao usuário. Atividades Básicas de Vida Diária (ABVD) são aquelas ações básicas e fundamentais para manter-se vivo, e estão diretamente relacionadas à sobrevivência e ao bem-estar do indivíduo. Tomar banho, vestir-se, alimentar-se, fazer higiene pessoal, ter controle da bexiga e intestino são apenas alguns exemplos de ABVDs. Enquanto Atividades Instrumentais de Vida Diária (AIVD) compreendem as atividades que dão suporte às atividades básicas de vida diária em ambientes domésticos ou públicos, sendo que essas exigem interações mais complexas que as ABVDs. Cuidar de outras pessoas, cuidar de animais de estimação, preparação de alimentos e limpeza de objetos utilizados para tanto e manutenção da casa (áreas interna e externa) são alguns exemplos de AIVDs.

\subsection{Mercado de Órteses, Próteses e Materiais Especiais (OPME) no Brasil}

Apesar de o mercado de órteses, próteses e materiais especiais se encontrar em crescimento, assim como boa parte dos outros mercados nacionais, tal crescimento é caracterizado como "descontrolado" por setores ligados à gestão e regulamentação de produtos e serviços hospitalares. Dados apontam que existe uma carência de regulamentação, padronização e ética para o mercado OPME no Brasil. Entretanto, mesmo em face de um cenário que cresce desordenadamente, existem avanços que devem ser considerados, como o fato de o país ser considerado $013^{\circ}$ no ranking mundial entre os melhores classificados, segundo dados publicados pela GTT Healthcare sobre o cenário nacional do mercado OPME.

Reconhecendo a necessidade de uma reforma no mercado OPME no Brasil o Ministério da Saúde, através da Portaria Interministerial no 38, de 8 de janeiro de 2015, fez um levantamento sobre a situação atual desse mercado, tendo por finalidade propor medidas para a reestruturação e ampliação da transparência dos processos envolvendo OPME, contemplando todos os segmentos envolvidos: produção, importação, distribuição, aquisição, utilização, tributação, avaliação e incorporação tecnológica, regulação de preços e aprimoramento da regulação clínica e de acesso aos dispositivos médicos. O material intitulado Grupo de Trabalho Interinstitucional sobre Órtese e Prótese - GTI OPME foi publicado em 7 de julho de 2015 e foi composto pelo Ministério da Saúde, Ministério da Fazenda, Ministério da Justiça e Conselhos Nacionais de Secretários de Saúde Estaduais e Municipais.

O plano de trabalho levantou o diagnóstico situacional do setor OPME no país e ainda traçou um plano estratégico de propostas de reestruturação do setor. Foram realizadas diversas reuniões do GTI, acompanhamento das CPIs do Congresso Nacional (Câmara e Senado) e ainda houve a participação de representantes de órgãos e entidades (públicas e privadas) e também de especialistas - a lista completa pode ser conferida no documento disponibilizado online pelo Ministério da Saúde, disponível em: <https://goo.gl/nmv734>.

\subsection{Autoestima e Estética}

Como citado anteriormente, autoestima se configura como sendo a capacidade de valorização e apreço que uma pessoa confere a si própria, o que lhe permite ter confiança em seus 
próprios pensamentos e atos. Com base nessa definição, é possível perceber a influência da autoestima, que é um importante recurso que o ser humano tem para viver bem, pois ela determina a forma como ele se relaciona consigo mesmo, com o mundo ao redor, como encara os desafios cotidianos e também como se expõe ou se protege de situações que vão exigir o exercício de seu controle emocional.

A autoestima ainda desempenha fundamental papel quando se trata da convivência familiar e entre amigos, relações de trabalho e contato social de forma geral. A autoestima nasce de forma única e pessoal, mas seu desenvolvimento se dá a partir do convívio com a realidade na qual o indivíduo está inserido, pois o modo como ele age e também como ele reage a estímulos externos pode, ao longo do tempo, influenciar na sua forma de entender a si próprio.

Quanto aos conceitos relacionados à estética, é importante citar logo de início que, como indica Gerhardt de Oliveira et al. (2007), Platão e Aristóteles questionaram o significado próprio da beleza e definiram o termo estética como sendo o estudo da beleza e a Filosofia da Arte. Para que a estética seja compreendida de uma forma mais ampla, deve-se levar em consideração não apenas os aspectos científicos, mas também aspectos sociais e artísticos. Nesse ponto, faz-se necessário complementar os conceitos apresentados com a ideia expressa por Aranha et al. (1993):

A estética é um ramo da filosofia que se ocupa das questões tradicionalmente ligadas à arte, como o belo, o feio, o gosto, os estilos e as teorias da criação e da percepção artísticas. Do ponto de vista estritamente filosófico, a estética estuda racionalmente o belo e o sentimento que este desperta nos homens. Dessa forma, surge o uso corrente, comum, de estética como sinônimo de beleza. (...) A palavra estética vem do grego aisthesis e significa "faculdade de sentir", "compreensão pelos sentidos", "percepção totalizante. (ARANHA et al., 1993, p. 200)

E ainda, conforme aponta Osborne (1970), existe uma divisão das qualidades que são atribuídas à arte em estéticas e não estéticas, em que as qualidades não estéticas são as que são percebidas da mesma forma por todos os que contemplam e apreciam determinada obra, enquanto as qualidades estéticas são aquelas que se modificam conforme a percepção do sujeito que a contempla. Complementando assim o que foi citado no texto introdutório em relação ao apontamento do filósofo alemão Kant (1980), de que o centro de existência do belo não está no objeto em si, mas no sujeito que o experiencia.

\section{Materiais e Estratégia de Pesquisa}

Como estratégia de pesquisa, adotou-se a análise qualitativa, por ser um método que foca na qualidade e natureza das informações coletadas, não em números. Por meio de pesquisa de campo foi possível observar fatos que ocorrem na realidade que é foco do trabalho.

Pretendendo alcançar o objetivo proposto para este trabalho, a metodologia foi fragmentada em quatro etapas: revisão de literatura, coleta de dados, análise de dados e estabelecimento da análise comparativa.

$\mathrm{Na}$ etapa inicial da pesquisa, foi realizada uma revisão de literatura abordando os temas design e emoção, tecnologia assistiva, mercado OPME no Brasil e também aspectos relacionados a estética e autoestima. A revisão de literatura foi realizada através de pesquisas bibliográficas por meio eletrônico. 
$\mathrm{Na}$ etapa referente à coleta de dados, foi realizada uma pesquisa com 12 pessoas no período de 20/02/2017 a 10/03/2017, se tratando de um questionário (composto por nove questões de múltipla escolha e uma questão aberta) que foi aplicado por meio eletrônico. A pesquisadora assegura que o preenchimento do questionário foi anônimo e confidencial.

Foram elaboradas dez perguntas, divididas em duas partes. Parte 1: cinco perguntas para levantamento de informações básicas sobre os indivíduos. Parte 2: cinco perguntas para levantamento de informações sobre o consumo e emoções relacionados ao consumo de próteses. As perguntas estão apresentadas na Figura 2, enquanto os resultados da pesquisa são apresentados na Figura 3.

Figura 2 - Perguntas que foram feitas e suas respectivas possibilidades de resposta

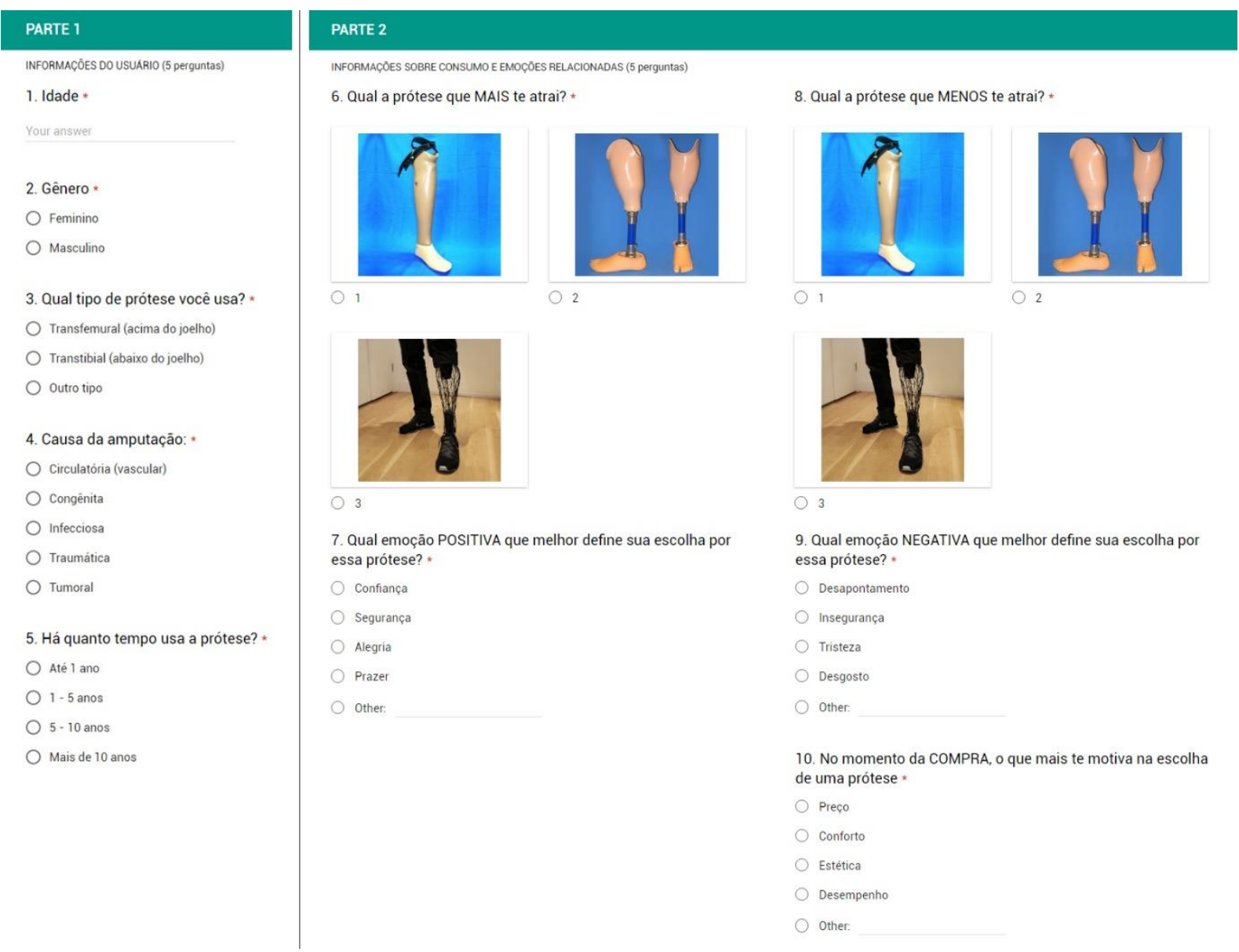

Fonte: elaborado pela autora - print screen do questionário hospedado no Google Forms 
Figura 3 - Resultados da aplicação do questionário

\section{PARTE 1}

1. Idade (12 responses)

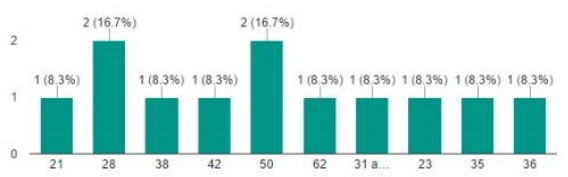

2. Gênero

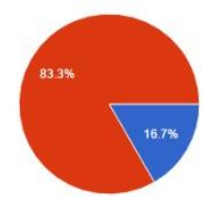

3. Qual tipo de prótese você usa?

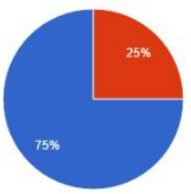

4. Causa da amputaçāo: (12 responses)

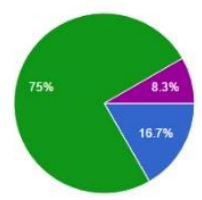

5. Há quanto tempo usa a prótese? (12 responses)

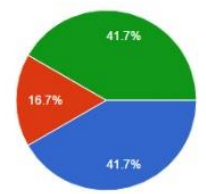

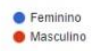

- Transtbial
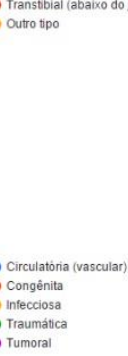

: Ate 1 ano
$-1 .-5$ anos
: -10 anos

\section{PARTE 2}

6. Qual a prótese que MAIS te atri?

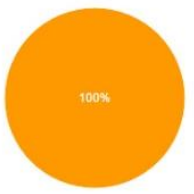

$::^{1}$

7. Qual emoçāo POSITIVA que melhor define sua escolha por essa prótese?
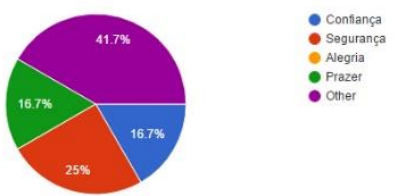

8. Qual a prótese que MENOS te atrai? (12 responses)

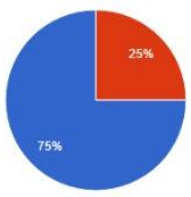

$: \begin{array}{ll}1 \\ :\end{array}$

9. Qual emoção NEGATIVA que melhor define sua escolha por essa prótese?
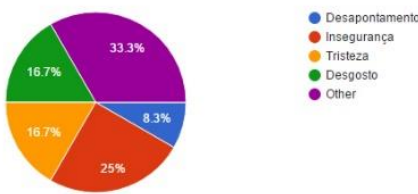

10. No momento da COMPRA, o que mais te motiva na escolha de uma prótese

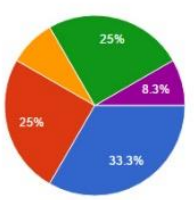

Fonte: elaborado pela autora - print screen do questionário hospedado no Google Forms

É importante esclarecer que a pesquisa não foi submetida para a avaliação e aprovação no Comitê de Ética em Pesquisa (CEP/CONEP). Conforme a Resolução no 510, de 07 de abril de 2016, do Conselho Nacional de Saúde, as pesquisas de opinião pública com participantes não identificados dispensam a avaliação pelo sistema CEP/CONEP.

Posteriormente foi feita a análise dos resultados obtidos por meio do instrumento de coleta de dados Google Forms, que fornece respostas com resumos automáticos. Assim, foi possível interpretar e analisar os dados obtidos, e também constatar que a maioria dos participantes são do gênero masculino. Os resultados ainda apontaram a idade média dos participantes, o tipo de prótese que usam, a causa da amputação e há quanto tempo, em média, o indivíduo faz uso de prótese. 
Com base nos resultados obtidos nas etapas anteriores, propõe-se o estabelecimento de uma análise comparativa, com base em uma fundamentação teórica sólida, com a finalidade de entender o comportamento do consumidor e suas preferências, buscando apontar o papel das emoções nesse processo.

\section{Apresentação, Análise e Discussão dos Resultados}

O levantamento de dados se deu a partir de informações fornecidas por um grupo de doze indivíduos que passaram por pelo menos um processo de amputação transfemural (acima do joelho) ou transtibial (abaixo do joelho). Apesar de não ter sido possível alcançar um número mais significativo de voluntários (devido à dificuldade de acesso e contato, e também pelo fato de que muitos indivíduos se recusaram a participar da pesquisa), os dados levantados permitiram conhecer melhor o perfil do indivíduo amputado que faz uso de prótese.

O grupo formado por 2 mulheres e 10 homens compreende uma faixa etária que vai dos 21 aos 62 anos de idade. Existem cinco causas possíveis de amputação, sendo elas causadas por questão circulatória (vascular), congênita, infecciosa, traumática e tumoral. As causas citadas pelos participantes foram: traumática (9 indivíduos), circulatória ( 2 indivíduos) e tumoral (1 indivíduo). Nove indivíduos passaram pelo processo de amputação transfemural e os três restantes pelo processo de amputação transtibial. Cinco indivíduos usam prótese há mais de 10 anos, dois usam há um tempo entre 1 e 5 anos e os cinco restantes usam há, no máximo, 1 ano. Todos esses dados foram levantados a partir das perguntas referentes a Parte 1 , que focou na coleta de informações básicas sobre os usuários.

Uma pesquisa sobre concerns se dá por meio de grupos focais, entrevistas e sessões gerativas (ÖZKARAMANLI; DESMET, 2012), e algumas técnicas podem ser utilizadas com o intuito de complementar as entrevistas, como metáforas visuais e observações. As metáforas visuais atuam como uma espécie de gatilho que estimula a lembrança de eventos passados, enquanto a observação ajuda na compreensão de um problema que o usuário talvez não consiga expressar tão bem.

No quesito metáforas visuais, o questionário apresentou três imagens que representavam os três tipos (estilos) de próteses transfemurais e transtibiais mais comumente utilizadas, propondo assim o estabelecimento de três grandes grupos de tipos de próteses indicadas em casos de amputação de perna: (A) prótese que reproduz a forma de uma perna humana, incluindo pé, mas limita um pouco as possibilidades de flexão de joelho, (B) prótese com o suporte para acomodação do coto, estrutura metálica aparente, incluindo pé e oferecendo mais possibilidades de flexão de joelho, e (C) prótese projetada por meio de escaneamento de membro referência (o processo de modelagem se dá a partir do membro intacto) e produzida por meio de impressão 3D, possibilitando exploração da superfície segundo preferências do usuário, considerando toda a questão mecânica relacionada ao movimento (marcha) e ainda possibilitando a flexão de joelho. 
Figura 4 - Tipos de prótese

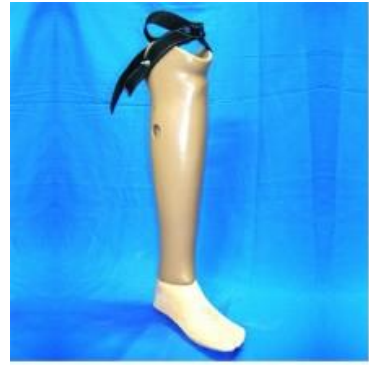

(A)

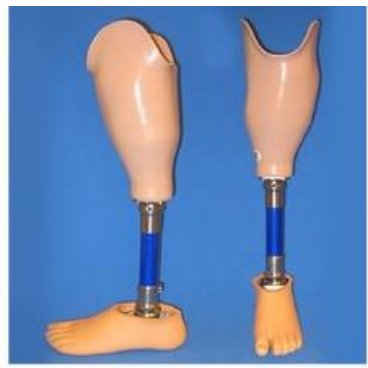

(B)

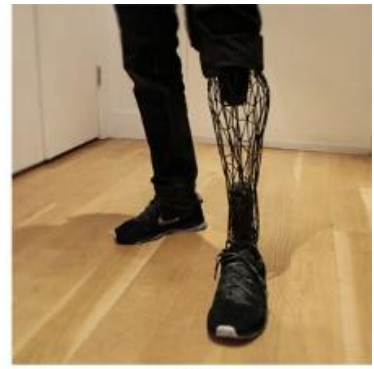

(C)

Fonte: (A) Hospital and Rehabilitation Ho Chi Minh City, disponível em: https://goo.gl/djJ0mR, acesso em dez. 2016. (B) Introduction to the Physiotherapy Management of Amputees, disponível em: https://goo.gl/tN3WRn, acesso em dez. 2016. (C) Exo Prosthetic Leg, disponível em: https://goo.gl/IrJ7Xe, acesso em dez. 2016.

No quesito observações, o questionário ofereceu aos entrevistados dois grupos de opções de respostas que consistiam em um grupo de emoções positivas e outro de emoções negativas, ambos fazendo referência aos mesmos produtos. A intenção foi focar nas emoções em si, para que não houvesse nenhum tipo de equívoco quanto a ato de identificar e apontar os tipos de emoções relacionadas a escolha de produtos, já que muitas vezes percepções (ou até mesmo alguns conceitos) podem facilmente ser confundidas com emoções. As emoções positivas e negativas foram elegidas com base nos conceitos apresentados por Chitturi (2009), que trabalha a questão das emoções no processo de projetar, a partir da perspectiva do consumidor.

A Parte 2 do questionário se dedicou ao levantamento de dados referentes a consumo e também às emoções relacionadas ao consumo de próteses. Nesse ponto foi possível perceber melhor como cada indivíduo reage às metáforas visuais oferecidas, tendo como base suas preferências pessoais. Quando perguntados sobre qual das três opções era a mais atraente, a resposta foi unânime, todos os indivíduos apontaram a opção C. E quando questionados sobre qual a emoção positiva que melhor definia a escolha, as respostas foram bem diversas. Três indivíduos apontaram Segurança como sendo a emoção que melhor definia o motivo da escolha, dois apontaram Confiança, outros dois justificaram sentir Prazer, e os cinco indivíduos restantes marcaram a opção "Outros", na qual puderam expressar melhor suas percepções (apesar de que em alguns pontos elas não expressam emoções de fato). Neste item a justificativa de escolha foi explicada pelas seguintes definições: estética, por necessidade, futurista, por ser mais diferente e moderna, satisfação. Para o indivíduo de 62 anos, a Estética (que na realidade não é uma emoção) foi o que mais o atraiu em relação à prótese $C$ e, novamente a Estética foi o que menos o atraiu em relação à prótese $\mathrm{B}$. Nota-se assim uma preocupação em relação à configuração visual do produto, apontando assim para questões relacionadas à autoestima, de forma a colocá-la num patamar de equivalência em relação ao desempenho e ao custo.

No terceiro momento foram apresentadas as mesmas opções de metáforas visuais, porém o questionamento foi o oposto, nesse ponto pediu-se para que os participantes apontassem qual a prótese que menos os atraía. Nove apontaram a opção $A$ enquanto os três restantes apontaram a opção B. Quando questionados sobre qual a emoção negativa que melhor definia a escolha, as respostas foram novamente bem diversas. Três disseram sentir Insegurança, dois sentiram Desgosto, outros dois sentiram Tristeza, um sentiu desapontamento e os quatro restantes optaram por descrever melhor suas percepções marcando a opção "Outros". Um dos quatro 
indivíduos se disse menos atraído pela opção $B$ e foi por questão estética. Os outros três indivíduos apontaram a opção A como sendo a menos atrativa. Um justificou dizendo que a considerava antiga e desatualizada. Outro disse que ela parecia tentar imitar uma perna de verdade e que isso dava a ela um ar muito falso. E o último disse que essa opção representava uma ilusão.

Para entender um pouco melhor sobre o comportamento dos indivíduos como consumidores, perguntou-se o qual a maior motivação no momento da compra de uma prótese, e aqui, mais uma vez, as respostas foram bem diversas. Quatro indivíduos disseram que era o Preço, três o Desempenho, três o Conforto, um optou por estética e o indivíduo restante optou pela opção "Outros", na qual apontou a relação entre Preço e Conforto como sua principal motivação no momento da compra.

É possível perceber, com as informações coletadas a partir da perspectiva de usuários reais, que o impacto emocional depende diretamente dos concerns do usuário, o que conduz à conclusão de que somente após uma investigação direta sobre a realidade na qual o público-alvo está inserido, pode ser possível compreender o papel do design no processo de potencializar as emoções que se pretende estimular ou evitar com determinado produto.

Apesar do fato de que indivíduos diferentes experimentam emoções também diferentes em relação a uma mesma situação ou um mesmo produto, o processo de elicitação (evocação, excitação, promoção) de emoções é universal, de acordo com Frijda (1986).

\section{Considerações Finais}

O consumo de produtos por motivações estéticas pode, muitas vezes, superar o consumo por motivações funcionais e também de desempenho, ainda mais se tratando de próteses, já que esse tipo de produto tem o poder de gerar diferentes tipos e intensidades de emoções, atuando inclusive como uma extensão da personalidade e identidade do usuário. Preço e desempenho deixam de ser as metas absolutas e passam a dividir importância com questões relacionadas a estética e conforto, como pôde ser visto através das respostas fornecidas pelos indivíduos que participaram da pesquisa. Dessa forma fica clara a necessidade de contemplar os aspectos emocionais referentes ao processo de escolha por parte dos usuários, levando em consideração que o conceito da peça, os aspectos ligados à usabilidade e desempenho, a possibilidade de customização e custo são fatores que interferem no poder de escolha a partir da perspectiva do usuário-consumidor.

\section{Referências}

ARANHA, Maria Lúcia de Arruda; MARTINS, Maria Helena Pires. Filosofando: Introdução à Filosofia. 2. ed. rev. e atual. São Paulo: Ed. Moderna, 1993.

CÂMARA TÉCNICA DE IMPLANTES. Definição de Órtese e Prótese. Disponível em: <https://goo.gl/WhHMDz>. Acesso em: 20 jan. 2017.

CENTRO DE TERAPIA OCUPACIONAL DO RIO DE JANEIRO. Atividades Básicas de Vida Diária. Disponível em: <https://goo.gl/CmRhkU>. Acesso em: 18 jan. 2017. 
CENTRO DE TERAPIA OCUPACIONAL DO RIO DE JANEIRO. Atividades Instrumentais de Vida Diária. Disponível em: <https://goo.gl/mZ3YsF>. Acesso em: 18 jan. 2017.

CHITTURI, R. Emotions by Design: A Consumer Perspective. International Journal of Design, 3 (2), p. 7-17, 2009.

CONSELHO NACIONAL DE SAÚDE (BRASIL). Resolução no 510, de 07 de abril de 2016. Brasília, 2016. Disponível em: <https://goo.gl/sxgLwS>. Acesso em: 24 jan. 2017.

DESMET, P.; HEKKERT, P. Framework of Product Experience. International Journal of Design, 1 (1): p. 57-66, 2007.

DESMET, P. Special Issue Editorial: Design \& Emotion. International Journal of Design, 3 (2): p. 1-6, 2009.

FRIJDA, N.H. The Emotions. Cambridge, Cambridge University Press, 544 p., 1986.

GERHARDT DE OLIVEIRA, Marília; Motta BERTOLLO, Rossiene; POZZA, Daniel Humberto; GAIÃO, Lêonilson; SOARES, Lívia Prates. A percepção do belo e a proporção divina. Revista da Academia Tiradentes de Odontologia, v.7, n. 6, p. 403-413. Porto, PORTUGAL: 2007.

GRUPO DE TRABALHO INTERINSTITUCIONAL SOBRE ÓRTESE E PRÓTESE - GTI OPME. Portaria Interministerial no 38, de 8 de janeiro de 2015. Brasília, 2015. Disponível em: <https://goo.gl/nmv734>. Acesso em: 26 jan. 2017.

GTT HEALTHCARE. Mercado de órteses e próteses - OPME no Brasil, dez. 2016. Disponível em: <https://goo.gl/zqrTOs>. Acesso em: 18 jan. 2017.

GTT HEALTHCARE. OPMEs: Da identificação da necessidade até a fabricação, jun. 2016. Disponível em: <https://goo.gl/g10NUY>. Acesso em: 18 jan. 2017.

HEKKERT, P. Design aesthetics: Principles of pleasure in product design. Psychology Science, 48 (2): p. 157-172, 2006.

KANT, Immanuel. Crítica do Juízo. São Paulo, Abril Cultural, 431 p., 1980.

LEITE, Ana Katharina. Tecnologia Assistiva: o "Bê a bá"!, dez. 2016. Disponível em: <https://goo.gl/SWNtyW>. Acesso em: 20 jan. 2017.

. Entenda por que a autoestima interfere tanto na sua vida, mar. 2011. Disponível em: <https://goo.gl/3XMX4Q>. Acesso em: 25 jan. 2017.

Metodologia Científica: tipos de pesquisa, ago. 2013. Disponível em: <https://goo.gl/D5Kils>. Acesso em: 12 dez. 2016.

OSBORNE, Harold. Aesthetics and Art Theory, an Historical Introduction. New York, E. P. Dutton \& Co., Inc., 1970.

ÖZKARAMANLI, D; DESMET, P. I Knew I Shouldn't, Yet I Did It Again! Emotion-driven Design as a Means to Motivate Subjective Well-being. Interaction. International Journal of Design, 6 (1): p. 27-39, 2012.

TONETTO, L.M.; COSTA, F.C.X. Design Emocional: conceitos, abordagens e perspectivas de pesquisa. Strategic Design Research Journal, 3 (4): p. 132-140, 2011. http://dx.doi.org/10.4013/sdrj.2011.43.04 
U.S. GOVERNMENT PRINTING OFFICE. 105th Congress Public Law 394, nov. 13, 1998. Assistive Technology Act of 1998. Disponível em: <https://goo.gl/noH7iY>. Acesso em: 18 jan. 2017.

WALD, J., ÁLVARO, R. Psychological factors in work-related amputation: considerations for rehabilitation counselors. Journal of Rehabilitation, 70 (4): p. 6-15, 2004. 